\title{
Linear and Nonlinear Regression Methods for Equilibrium Modelling of $p$-Nitrophenol Biosorption by Rhizopus oryzae: Comparison of Error Analysis Criteria
}

\author{
Zvezdelina Lyubenova Yaneva, ${ }^{1,2}$ Bogdana Koumanova Koumanova, ${ }^{1}$ \\ and Nedyalka Valkanova Georgieva ${ }^{2}$ \\ ${ }^{1}$ Department of Chemical Engineering, University of Chemical Technology and Metallurgy, 8 Kliment Ohridski, 1756 Sofia, Bulgaria \\ ${ }^{2}$ Chemistry Unit, Department of Pharmacology, Animal Physiology and Physiological Chemistry, Faculty of Veterinary Medicine, \\ Trakia University, Students Campus, 6000 Stara Zagora, Bulgaria
}

Correspondence should be addressed to Nedyalka V. Georgieva; nvgeorgieva@vmf.uni-sz.bg

Received 13 June 2012; Accepted 9 August 2012

Academic Editor: Javier Hernandez-Borges

Copyright (C) 2013 Zvezdelina L. Yaneva et al. This is an open access article distributed under the Creative Commons Attribution License, which permits unrestricted use, distribution, and reproduction in any medium, provided the original work is properly cited.

\begin{abstract}
The study assessed the applicability of Rhizopus oryzae dead fungi as a biosorbent medium for p-nitrophenol ( $p$-NP) removal from aqueous phase. The extent of biosorption was measured through five equilibrium sorption isotherms represented by the Langmuir, Freundlich, Redlich-Peterson, multilayer and Fritz-Schlunder models. Linear and nonlinear regression methods were compared to determine the best-fitting equilibrium model to the experimental data. A detailed error analysis was undertaken to investigate the effect of applying seven error criteria for the determination of the single-component isotherm parameters. According to the comparison of the error functions and to the estimation of the corrected Akaike information criterion $\left(\mathrm{AIC}_{\mathrm{C}}\right)$, the Freundlich equation was ranked as the first and the Fritz-Schlunder as the second best-fitting models describing the experimental data. The present investigations proved the high efficiency (94\%) of Rhizopus Oryzae as an alternative adsorbent for $p$-NP removal from aqueous phase and revealed the mechanism of the separation process.
\end{abstract}

\section{Introduction}

Nitrophenols are classified as moderately to highly toxic even at low concentrations when present in wastewaters. Thus, they are a source of serious social and hygienic problems as important occupational and environmental pollutants [1]. The undesirable impact of these recalcitrant organics on organisms, as well as their considerable release through industrial wastes, provoked the researchers to search for innovative effective technologies for the remediation of nitrophenols-rich wastes before their discharge into natural water streams [2]. Nitroaromatic compounds are widely used as pesticides, explosives, solvents, and intermediates in the synthesis of dyes and other chemicals. Many of these compounds and their transform products are of significant toxicological concern [3].

The monosubstituted $p$-nitrophenol ( $p$-NP) could enter the environment during its production and use in hightemperature coal conversion, as a byproduct in the enzymatic hydrolysis of parathion, methyl parathion, and N-acetyl$p$-amino-phenol. It is also found in suspended particulate matter in the atmosphere, originating mostly from secondary photochemical reactions in the air [3]. The toxicity of $p$ nitrophenol on biological systems has led to its classification as a priority pollutant by the United States Environmental Protection Agency (EPA) [4].

The literature reports a number of studies on the efficiency of various adsorbents for phenols and substituted phenols removal from wastewaters [5]. The high adsorption activity of various biopolymers (unmodified/modified chitosan, lignin, etc) towards phenols, chlorophenols, and dyes was scientifically proven [6-8]. Fungi belonging to the genera Rhizopus and Penicillium have already been studied as a potential biomass for the removal of heavy metals $(\mathrm{Cu}$, $\mathrm{Zn}, \mathrm{Cr}, \mathrm{Cd}$ ) [9-11], nonylphenol [12], polycyclic aromatic hydrocarbons (PACs) [13], cyanide [14], and dyes from aqueous solutions [8]. The saprophytic microorganisms Rhizopus 
oryzae were proved as a good adsorbent for the removal of the organochloropesticide lindane [15], and rhodamine B from water [16].

The walls of $R$. oryzae consist of chitin and chitosan. The mechanism of biosorption is quite complicated. The capacity of dead cells might be higher, equal or even lower when compared to that of live cells. In most cases, however, the application of dead biomass is more effective [17]. Chitin is the second most abundant natural carbohydrate polymer next to cellulose. Many applications of R. oryzae are due to the secondary amino groups of chitosan which show polycationic chelating and film-forming properties along with high solubility in dilute acetic acid [18].

Over the past few decades, linear regression has been developed as a major option in designing adsorption systems [19-23]. However, recent investigations have indicated the growing discrepancy (between the predictions and experimental data) and disability of the model, propagating towards a different outcome [24]. A number of error functions (sum of the squares of errors, ERRSQ; hybrid fractional error function, HYBRID; Marquardt's percent standard deviation, MPSD; average relative error, ARE; Sum of the absolute errors, EABS; chi-square function, $\chi^{2}$; Akaike information criterion, AIC, etc.) were highlighted and discussed for the comparisons of linear and nonlinear isotherm models [2426]. According to recent studies, the expanding of the nonlinear isotherms represents a potentially viable and powerful tool, leading to the superior improvement in the area of adsorption science [27]. However, according to Foo and Hameed [24], further explorations in this area are recommended. Moreover, these error estimating functions do not take into account the number of parameters in the models. Hence, they cannot be used for selection of model(s) appropriateness and determination of its/their magnitude. The literature reports studies applying the Akaike information criterion (AIC) for model selection and ranking in the field of veterinary medicine [28], genetics [29], aquatic biogeochemical modeling [30], FTIR spectroscopy [31], pharmacy [32], and so forth. The number of studies subjected to the applicability of AIC for statistical modelling of toxic organics sorption on alternative sorbents, however, is limited.

In this context, the scope of the present study was to investigate the applicability of Rhizopus oryzae as an alternative "ecofriendly" adsorbent for $p$-nitrophenol removal from aqueous phase at equilibrium conditions. Linear and nonlinear regression analysis was performed to determine model parameters. Seven error functions were applied to evaluate, compare, and rank the feasibility of the five applied isotherm models (Langmuir, Freundlich, Redlich-Peterson, multilayer, and Fritz-Schlunder).

\section{Materials and Methods}

2.1. Adsorbate. $p$-Nitrophenol ( $p$-NP) (Merck, 99\%), without further purification, was used as a sorbate in the investigations. Its physicochemical characteristics are presented elsewhere [33].

2.2. Adsorbent. Rhizopus oryzae used in the recent study as a sorbent was supplied by the International Mycological
Institute in Surrey, UK, in the form of IMI strain 266680. The microorganisms were isolated from a soil in Sri Lanka. The spores dried at low temperature were reactivated and cultivated in malt extract $\left(17 \mathrm{~g} \mathrm{dm}^{-3}\right.$ malt extract and $3 \mathrm{~g} \mathrm{dm}^{-3}$ mycological peptone, dissolved in distilled water at $\mathrm{pH} 5.4 \pm$ 0.2 ). The malt extract was inoculated by a standard sterile method and incubated at $32^{\circ} \mathrm{C}$ for 3 days in a platform shaker at $175 \mathrm{rpm}$. Three ceramic granules were added to each of the batch reactors with malt extract to limit the microorganisms threadlike growth. The biomass obtained was precisely washed out consecutively with maternal lye and distilled water and then dried in an oven at $50^{\circ} \mathrm{C}$. The dried biomass was ground in a hammer mill and screened. The fraction used in the recent investigations was $d_{p} 0.15-0.50 \mathrm{~mm}$.

2.3. Equilibrium Studies. The equilibrium experiments were accomplished using model solutions of $p$-NP in distilled water. The investigations were carried out at temperature $19 \pm$ $1^{\circ} \mathrm{C}$ and $\mathrm{pH}$ 6.1. Solutions were in the concentration range $C_{o}$ $5-25 \mathrm{mg} \mathrm{dm}^{-3}$. Known amounts of Rhizopus oryzae, $0.3 \mathrm{~g}$, were added to $100 \mathrm{~cm}^{3}$ of the model solutions in screw cap jars. The jars were shaken on a platform shaker. The solute from each jar was then filtered. The residual $p$-NP concentrations in the liquid phase $\left(C_{e}\right)$ were determined spectrophotometrically. All investigations were performed in triplicate. The corresponding values of $p$-NP solid phase concentrations $\left(q_{e}\right)$ were calculated by the mass balance:

$$
\left(C_{o}-C_{e}\right) \cdot V=\left(q_{e}-q_{o}\right) \cdot w
$$

where $C_{o}, \mathrm{mg} \mathrm{dm}^{-3}$, is the initial adsorbate concentration in the liquid phase, $q_{o}=0$, and $w, g$, is the adsorbent mass.

SPECORD UV-VIS, Carl Zeiss Jena, spectrophotometer was used for concentration determinations at maximum absorption wavelength $\lambda 228 \mathrm{~nm}$. The $\mathrm{pH}$ was measured using an LHP 403T TACUSSEL pH-meter. Blanks containing no adsorbate and replicates of each adsorption point were used for each series of experiments.

2.4. Isotherm Modeling. The design and efficient operation of adsorption processes require equilibrium adsorption data for use in kinetic, dynamic, and mass transfer models [34]. In order to optimize the design of a specific sorbate/sorbent system, it is important to establish the most appropriate correlation for the experimental equilibrium data [35].

The biosorption behavior of $p$-NP on $R$. oryzae in the present research was modelled by the Langmuir, Freundlich, Redlich-Peterson, multilayer, and Fritz-Schlunder (fourparameter) isotherm equations (Table 1).

2.5. Error Analysis. In the present study, linear and nonlinear regression analysis was performed to determine the values of the isotherm model parameters. Six different error functions ( $R^{2}$, ERRSQ, HYBRID, MPSD, ARE, and EABS) were examined to evaluate the applicability of each model isotherm equation to the experimental data (Table 2) using the solver add-in functions of Microsoft Excel software. 
TABLE 1: Mathematical equations of the applied single component isotherm models.

\begin{tabular}{|c|c|c|c|c|c|}
\hline Isotherm model & & Nonlinear form & & Linear expression & Plot \\
\hline Langmuir [36] & (1) & $q_{e}=\frac{K_{L} c_{e}}{1+a_{L} c_{e}}$ & (2) & $\frac{c_{e}}{q_{e}}=\frac{1}{K_{L}}+\frac{a_{L}}{K_{L}} c_{e}$ & $\frac{c_{e}}{q_{e}}$ versus $c_{e}$ \\
\hline Freundlich [37] & (3) & $q_{e}=K_{F} \cdot c_{e}^{n_{F}}$ & (4) & $\log q_{e}=\log K_{F}+n_{F} \cdot \log c_{e}$ & $\log q_{e}$ versus $\log c_{e}$ \\
\hline $\begin{array}{l}\text { Redlich and } \\
\text { Peterson [38] }\end{array}$ & (5) & $q_{e}=\frac{K_{R} \cdot c_{e}}{1+a_{R} c_{e}^{b}}$ & (6) & $\ln \left(K_{R} \frac{c_{e}}{q_{e}}-1\right)=b \ln \left(c_{e}\right)+\ln \left(a_{R}\right)$ & $\ln \left(K_{R} \frac{c_{e}}{q_{e}}-1\right)$ versus $\ln \left(c_{e}\right)$ \\
\hline Multilayer [39] & (7) & $q_{e}=\frac{Q_{m} K_{1} c_{e}}{\left(1-K_{2} c_{e}\right)\left[1+\left(K_{1}-K_{2}\right) c_{e}\right]}$ & & $\begin{array}{c}\text { Second-order polynomial form } \\
\frac{c_{e}}{q_{e}}=\frac{\begin{array}{l}c_{e}^{2}\left(K_{2}^{2}-K_{1} K_{2}\right)+c_{e}\left(K_{1}-2 K_{2}\right)+1 \\
Q_{m} K_{1}\end{array}}{}\end{array}$ & $\frac{c_{e}}{q_{e}}$ versus $c_{e}$ \\
\hline $\begin{array}{l}\text { Fritz and } \\
\text { Schluender [40] }\end{array}$ & (9) & $q_{e}=\frac{A \cdot c_{e}{ }^{\alpha}}{1+B \cdot c_{e}^{\beta}}$ & & - & - \\
\hline
\end{tabular}

\section{Results and Discussion}

In order to assess the fate of nitrophenols in wastewater and to control their mobility and reactivity during remediation processes, the sorption behaviour and mechanism of these toxic contaminants must be understood and revealed. The knowledge of sorbate/sorbent adsorption behaviour at equilibrium is essential for environmental engineering and science as the derived isotherms reveal the specific relation between the pollutant concentration and its uptake degree by the solid phase at constant temperature.

In this section, among the five studied isotherms models, the best-fitting one was determined by the use of seven well-known error functions to calculate the error deviation between experimental and predicted equilibrium adsorption data, after both linear and nonlinear analysis. In all of the error methods it was assumed that both the liquid phase concentration and the solid phase concentration contribute equally to weighting the error criterion for the model solution procedure. The experimental investigations were conducted at biomass concentration $m 3.00 \mathrm{~g} \mathrm{dm}^{-3}$.

The values of the model parameters and the isotherm error deviation data for the Langmuir, Freundlich, and Redlich-Peterson equations determined by linear regression analysis and for the multilayer model obtained through the second-order polynomial form of (7) (see Table 1), are presented in Table 3.

Alternative isotherm parameters were also determined by nonlinear regression using five error functions (ERRSQ, HYBRID, MPSD, ARE, and EABS) and the corrected Akaike information criterion $\left(\mathrm{AIC}_{\mathrm{C}}\right)$. The values of the Langmuir, Freundlich, Redlich-Peterson, multilayer and FritzSchlunder model constants and the isotherm error deviation data are presented in Table 4.

The experimental data points of $p$-NP adsorption on Rhizopus oryzae dead biomass (Figures 1,2, 4, and 5) outlined a distinct steep vertical section in the low-concentration region, where a sharp leap of nitrophenol solid phase concentration from $q_{e} 0$ to $2.63 \mathrm{mg} \mathrm{g}^{-1}$ was distinguished. Consequently, higher extent of adsorption during the initial stages of the process could be expected. Besides, a clearly

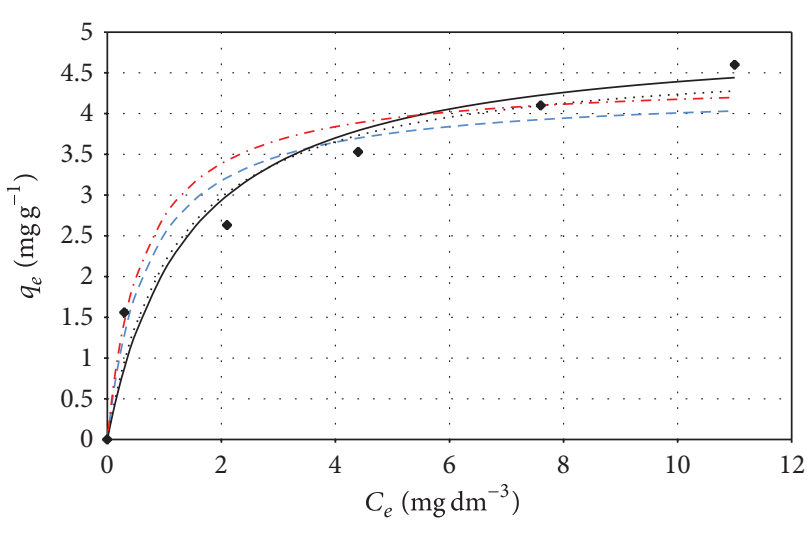

$$
\begin{aligned}
& \text { - Exp. data } \quad \text { … Langmuir-ERRSQ } \\
& \text {-- Langmuir-HYBRID ...- Langmuir-EABS } \\
& \text { - Langmuir-LTFM }
\end{aligned}
$$

FIGURE 1: Experimental equilibrium data and Langmuir isotherms of $p$-NP biosorption on $R$. oryzae dead biomass $\left(m 3.00 \mathrm{~g} \mathrm{dm}^{-3}, \mathrm{pH}\right.$ $6.1 \pm 0.2, T 19 \pm 2^{\circ} \mathrm{C}$ ).

marked plateau, that is, a horizontal section in the higher concentration range, was not observed. The latter could be interpreted by means of the presence of a number of vacant active sites, as well as a larger continuance of the adsorption process in the later stages. The above-stated assumptions were consistent with the higher values of the equilibrium constant for the first layer adsorption $\left(K_{1} 1.935\right.$ : linear regression; $K_{1}$ 2.7971-3.2225: nonlinear regression) than that for multilayer sorption $\left(K_{2}\right.$ 0.026: linear regression; $K_{2}$ 0.0265-0.0336: nonlinear regression), calculated by the multilayer model (Tables 3 and 4). The experimentally established maximum equilibrium capacity of the biomass was $q_{e} 4.6 \mathrm{mgg}^{-1}$, the monolayer capacity according to the linear Langmuir model $-K_{L} / a_{L} 5.01 \mathrm{mg} \mathrm{g}^{-1}$ (Table 3), and according to the nonlinear model $-K_{L} / a_{L} 4.28-7.91 \mathrm{mgg}^{-1}$ (Table 4). The second polynomial form of the multilayer equation predicted a maximum monolayer adsorption capacity- $Q_{m} 3.399 \mathrm{mg} \mathrm{g}^{-1}$ (Table 3), while the values of this parameter calculated by 
TABLE 2: Error functions used to discriminate between models.

\begin{tabular}{|c|c|c|c|}
\hline Error function & & Definition & References \\
\hline \multirow{2}{*}{ Coefficient of determination $\left(R^{2}\right)$} & \multirow{2}{*}{$(10)$} & $\sum_{i=1}^{p}\left(q_{e}^{\bmod }-\bar{q}_{e}^{\exp }\right)_{i}^{2}$ & \multirow{2}{*}[24,25,41]{} \\
\hline & & $\sum_{i=1}^{p}\left[\left(q_{e}^{\bmod }-\bar{q}_{e}^{\exp }\right)_{i}^{2}+\left(q_{e}^{\bmod }-q_{e}^{\exp }\right)_{i}^{2}\right]$ & \\
\hline Sum of the squares of errors (ERRSQ) & $(11)$ & $\sum_{i=1}^{p}\left(q_{e}^{\bmod }-q_{e}^{\exp }\right)_{i}^{2}$ & {$[34]$} \\
\hline $\begin{array}{l}\text { Hybrid fractional error function } \\
\text { (HYBRID) }\end{array}$ & $(12)$ & $\frac{100}{p-n} \sum_{i=1}^{p}\left[\frac{\left(q_{e}^{\exp }-q_{e}^{\bmod }\right)_{i}^{2}}{q_{e}^{\exp }}\right]_{i}$ & {$[42]$} \\
\hline $\begin{array}{l}\text { Marquardt's percent standard } \\
\text { deviation (MPSD) }\end{array}$ & $(13)$ & $100\left(\sqrt{\frac{1}{p-n}} \sum_{i=1}^{p}\left[\frac{\left(q_{e}^{\exp }-q_{e}^{\bmod }\right)_{i}^{2}}{q_{e}^{\exp }}\right]_{i}\right)$ & {$[43,44]$} \\
\hline Average relative error (ARE) & $(14)$ & $\frac{100}{p} \sum_{i=1}^{p}\left[\frac{\left(q_{e}^{\exp }-q_{e}^{\bmod }\right)_{i}^{2}}{q_{e}^{\exp }}\right]_{i}$ & {$[24,45]$} \\
\hline Sum of the absolute errors (EABS) & $(15)$ & $\sum_{i=1}^{p}\left(q_{e}^{\exp }-q_{e}^{\bmod }\right)_{i}$ & {$[46]$} \\
\hline $\begin{array}{l}\text { Corrected Akaike information } \\
\text { criterion }\left(\mathrm{AIC}_{\mathrm{C}}\right)\end{array}$ & $(16)$ & $\mathrm{AIC}+\left[\frac{2 n(n+1)}{p-n-1}\right]$ & \\
\hline & $(17)$ & where AIC $=2 n-p\left[\ln \left(\frac{\text { SSR }}{(p-n)}\right)\right]$ & {$[46-48]$} \\
\hline Akaike weight for the $i$ th model $\left(\lambda_{i}\right)$ & $(18)$ & $\lambda_{i}=\frac{\exp \left(-(1 / 2) \Delta_{i}\right)}{\sum_{i=1}^{R} \exp \left(-(1 / 2) \Delta_{i}\right)}$ & \\
\hline & (19) & where $\Delta_{i}=\mathrm{AIC}_{C i}-\min \mathrm{AIC}_{\mathrm{C}}$ & \\
\hline
\end{tabular}

TABLE 3: Isotherm error deviation data related to the biosorption of $p$-NP on $R$. oryzae dead biomass using seven commonly applied error functions-linear regression analysis.

\begin{tabular}{|c|c|c|c|c|}
\hline Model & Langmuir & Freundlich & Redlich and Peterson & Multilayer (second-order polynomial form) \\
\hline \multirow{3}{*}{ Parameters } & $K_{L} 3.535$ & $K_{F} 2.208$ & $K_{R} 1115.864$ & $K_{1} 1.935$ \\
\hline & $a_{L} 0.705$ & $n_{F} 0.303$ & $a_{R} 533.949$ & $K_{2} 0.026$ \\
\hline & & & $b 0.666$ & $Q_{m} 3.399$ \\
\hline \multicolumn{5}{|c|}{ Error functions } \\
\hline$R^{2}$ & 0.9833 & 0.9956 & 0.9997 & 0.9967 \\
\hline ERRSQ & 0.7090 & 0.0255 & 0.5987 & 0.1827 \\
\hline HYBRID & 12.639 & 0.3040 & 19.1130 & 4.4978 \\
\hline MPSD & 35.5410 & 5.5138 & 58.3339 & 31.9740 \\
\hline ARE & 14.3110 & 2.0128 & 10.3833 & 7.1261 \\
\hline EABS & 0.7156 & 0.1006 & 0.5192 & 0.3563 \\
\hline
\end{tabular}

Note. The highest $R^{2}$ and the lowest ERRSQ, HYBRID, MPSD, ARE, and EABS are in bold. 
TABLE 4: Values of Langmuir, Freundlich, Redlich and Peterson, Multilayer, and Fritz and Schlunder model parameters for the system $p$-NPRhizopus Oryzae obtained through nonlinear regression analysis and error deviation data using six error functions.

\begin{tabular}{|c|c|c|c|c|c|c|c|}
\hline & ERRSQ & HYBRID & MPSD & $\mathrm{ARE}$ & EABS & $\mathrm{AIC}_{\mathrm{C}}$ & $\lambda_{i}$ \\
\hline \multicolumn{8}{|c|}{ Langmuir model } \\
\hline$K_{L}$ & 3.9939 & 6.1036 & 6.1037 & 6.1038 & 7.1577 & & \\
\hline$a_{L}$ & 0.8428 & 1.4228 & 1.4228 & 1.4228 & 1.6142 & & \\
\hline Error & 0.6678 & 8.8101 & 29.6806 & 2.5861 & 1.6665 & 2.49 & $4.75 \times 10^{3}$ \\
\hline \multicolumn{8}{|c|}{ Freundlich model } \\
\hline$K_{F}$ & 2.1825 & 2.1945 & 2.1946 & 2.1946 & 2.2393 & & \\
\hline$n_{F}$ & 0.3110 & 0.3073 & 0.3073 & 0.3073 & 0.3002 & & \\
\hline Error & 0.0226 & 0.2928 & 5.4105 & 0.1757 & 0.2210 & -14.44 & 1.00 \\
\hline \multicolumn{8}{|c|}{ Redlich and Peterson model } \\
\hline$K_{R}$ & 1307.7861 & 1170.0995 & 1018.8770 & 1018.6101 & 1000.0155 & & \\
\hline$a_{R}$ & 588.4872 & 531.9036 & 463.0101 & 462.8754 & 572.1642 & & \\
\hline$b$ & 0.6974 & 0.6937 & 0.6938 & 0.6938 & 0.5793 & & \\
\hline Error & 0.0255 & 0.4483 & 6.7061 & 0.1799 & 1.2184 & 8.19 & $8.21 \times 10^{4}$ \\
\hline \multicolumn{8}{|c|}{ Multilayer model } \\
\hline$K_{1}$ & 2.8903 & 3.2225 & 3.2224 & 3.2224 & 2.7971 & & \\
\hline$K_{2}$ & 0.0317 & 0.0336 & 0.0336 & 0.0336 & 0.0265 & & \\
\hline$Q_{m}$ & 3.1784 & 3.0834 & 3.0834 & 3.0834 & 3.4010 & & \\
\hline Error & 0.1218 & 2.0060 & 14.1635 & 0.8024 & 0.5022 & 16.01 & $4.09 \times 10^{6}$ \\
\hline \multicolumn{8}{|c|}{ Fritz and Schlunder model } \\
\hline$A$ & 4.4335 & 4.5110 & 5.9346 & 3.5962 & 2.7281 & & \\
\hline$\alpha$ & 0.3109 & 0.3073 & 0.3073 & 0.3075 & 0.2956 & & \\
\hline$B$ & 1.0314 & 1.0555 & 1.7042 & 0.6388 & 0.2182 & & \\
\hline$\beta$ & $-6.7 \times 10^{-6}$ & $-8.5 \times 10^{-9}$ & $-2.6 \times 10^{-5}$ & 0.0004 & -0.0263 & & \\
\hline Error & 0.0226 & 0.8783 & 9.3716 & 0.1757 & 0.2213 & -10.97 & 5.67 \\
\hline
\end{tabular}

Note. The lowest ERRSQ, HYBRID, MPSD, ARE, EABS, and $\mathrm{AIC}_{\mathrm{c}}$ are in bold.

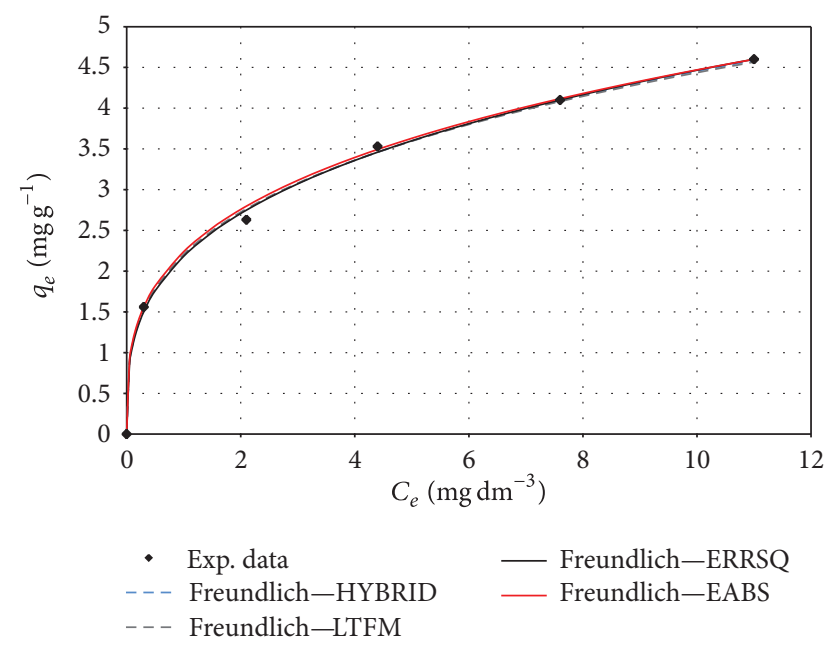

FIGURE 2: Experimental equilibrium data and Freundlich isotherms of $p$-NP biosorption on $R$. oryzae dead biomass $\left(m 3.00 \mathrm{~g} \mathrm{dm}^{-3}, \mathrm{pH}\right.$ $\left.6.1 \pm 0.2, T 19 \pm 2^{\circ} \mathrm{C}\right)$.

applying the nonlinear approach ranged between $Q_{m} 3.0834$ and $3.401 \mathrm{mg} \mathrm{g}^{-1}$ (Table 4).

The comparative analysis between the values of the error functions, obtained through the linear approach, outlined the three-parameter Redlich-Peterson model as the one with the highest $R^{2} 0.9997$ (Table 3). However, the Freundlich equation characterized with the lowest ERRSQ, HYBRID, ARE, MPSD and EABS error values. The data from Table 4 showed analogous tendency. Hence, is seemed that the Freundlich equation was the most suitable model presenting the most satisfactory description of the studied biosorption phenomenon.

Statistically, it is expected that the higher the number of parameters in a model equation, the closer the theoretical estimates should be to the empirical data. Moreover the error functions HYBRID and MPSD could be accepted as the most indicative, adequate and essentially meaningful when determining the best fit isotherm model, as the number of the isotherm parameters is accounted only by them [35]. The data in Tables 3 and 4, however, displayed the contrary as the three-parameter (Redlich-Peterson and multilayer) and the four-parameter (Fritz-Schlunder) models characterized with lower extend of suitability to the experimental data points due to the higher error values.

To prove the latter observations, the modes of the experimental and model isotherms obtained on the basis of the linear and nonlinear approach were also compared (Figure $1,2,4,5)$. Obviously, the Langmuir isotherms presented in Figure 1 did not correlate the experimental equilibrium data 


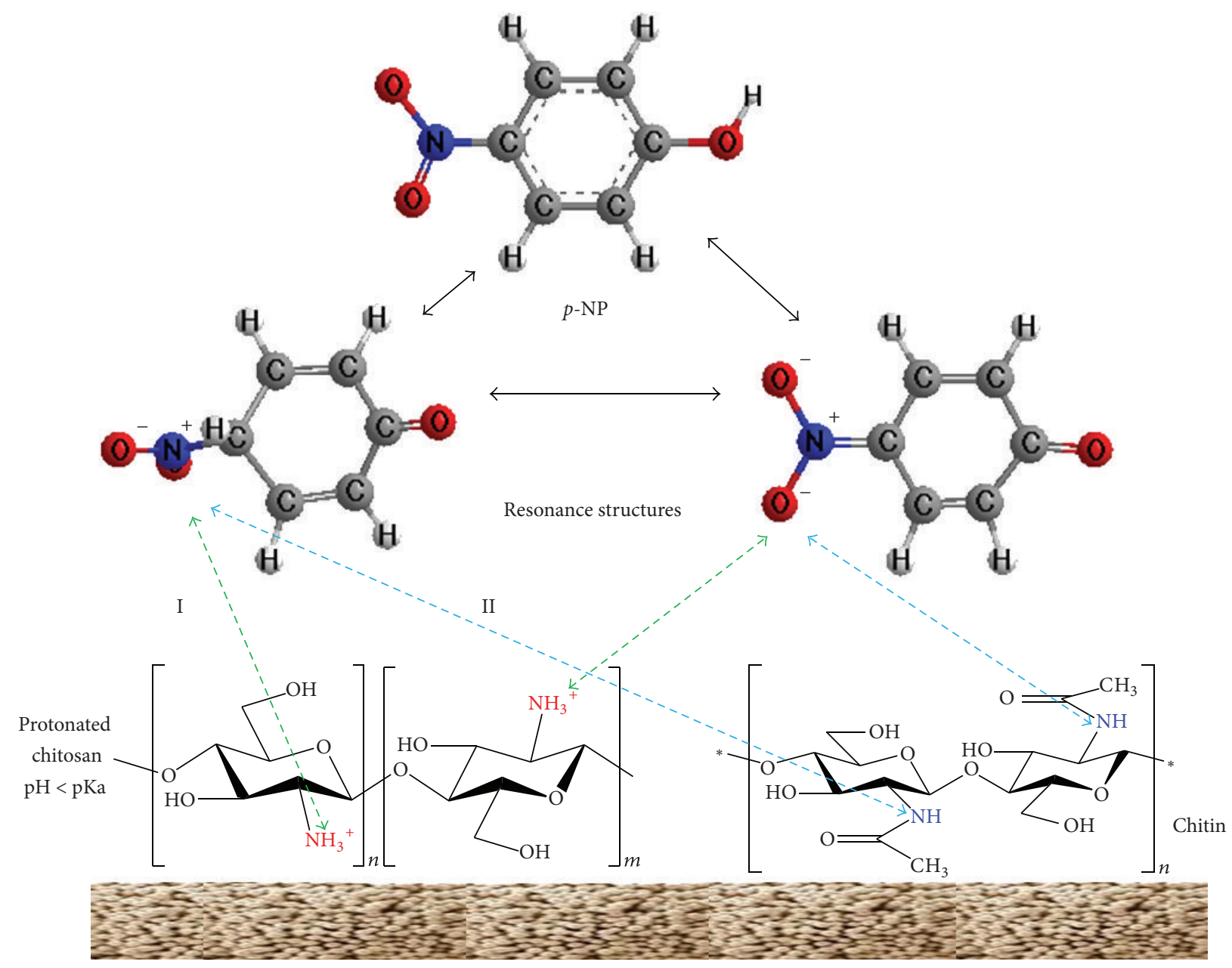

Rhizopus oryzae dead biomass

FIGURE 3: The proposed mechanism of $p$-NP biosorption by $R$. oryzae dead biomass. Note. I: chemical interactions between protonated chitosan $-\mathrm{NH}_{3}$ groups and $p$-NP functional groups; II: chemical interactions between amine nitrogens of chitin.

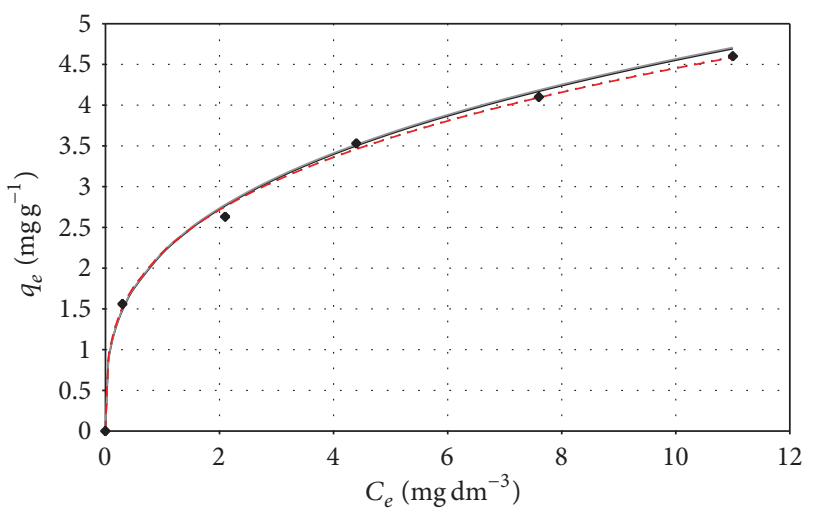

$\begin{array}{ll}\text { - } & \text { exp. data } \\ \text { - FSch - ERRSQ } & \text { - FSch - MPSD } \\ \text {..... } & \text { FSch - HYBRID }\end{array}$

FIGURE 4: Experimental equilibrium data and multilayer isotherms of $p$-NP biosorption on $R$. oryzae dead biomass using $\left(m 3.00 \mathrm{~g} \mathrm{dm}^{-3}, \mathrm{pH} 6.1 \pm 0.2, \mathrm{~T} 19 \pm 2^{\circ} \mathrm{C}\right)$. satisfactorily. It was observed that the HYBRID and EABS methods yielded the best fit in the low concentration range, while the LTFM isotherm could be applied for modeling the high concentration region.

Among the five applied equations, the Freundlich (Figure 2) and Fritz-Schlunder (Figure 5) isotherms could be identified as the most suitable for modelling the equilibrium sorption behaviour of $p$-NP on $R$. oryzae covering the entire concentration range. Besides, the individual model curves, derived on the basis of the studied error functions, practically coincided in both cases. Considering the theoretical bases of the Freundlich model, the studied separation process could be described either as non-ideal and reversible sorption, not restricted to monolayer formation on heterogeneous surface, or as multilayer sorption with non-uniform distribution of adsorption heat and affinities over the heterogeneous surface [24]. Besides, as the value of the parameter $n_{F}$ is below unity according to all implemented error analysis procedures, it is indicative of a chemisorption process. 
TABLE 5: Biosorption capacities of $R$. oryzae-based biosorbents towards varous heavy metals and priority organic pollutants.

\begin{tabular}{|c|c|c|c|c|c|}
\hline \multirow{2}{*}{ Biosorbent } & \multirow{2}{*}{ Sorbate } & \multirow{2}{*}{$q_{\max }, \mathrm{mgg}^{-1}$} & \multicolumn{2}{|c|}{ System parameters } & \multirow{2}{*}{ References } \\
\hline & & & $C_{o}, \mathrm{mg} \mathrm{dm}^{-3}$ & $m, \mathrm{~g} \mathrm{dm}^{-3}$ & \\
\hline R. oryzae dried biomass & Cr, As & 2.0 & 50.0 & 1.0 & [9] \\
\hline R. oryzae dried biomass & $\mathrm{Zn}$ & 11.0 & 50.0 & 1.0 & [9] \\
\hline R. oryzae dried biomass & $\mathrm{Cu}$ & 17.0 & 50.0 & 1.0 & [9] \\
\hline R. oryzae viable biomass & $\mathrm{Cu}$ & 12.4 & 50.0 & 1.0 & {$[11]$} \\
\hline R. oryzae cell walls & Rhodamine B & 7.6 & 100.0 & 4.0 & {$[16]$} \\
\hline R. oryzae biomass & Lindane & 0.375 & 1.0 & 1.7 & {$[15]$} \\
\hline R. oryzae biomass & Malathion & 0.445 & 1.5 & 2.0 & [49] \\
\hline R. oryzae fungi & Reactive Black 5 & 157.82 & 250.0 & 1 & {$[50]$} \\
\hline R. oryzae dead biomass & p-Nitrophenol & 4.5 & 25.0 & 3 & Present study \\
\hline
\end{tabular}

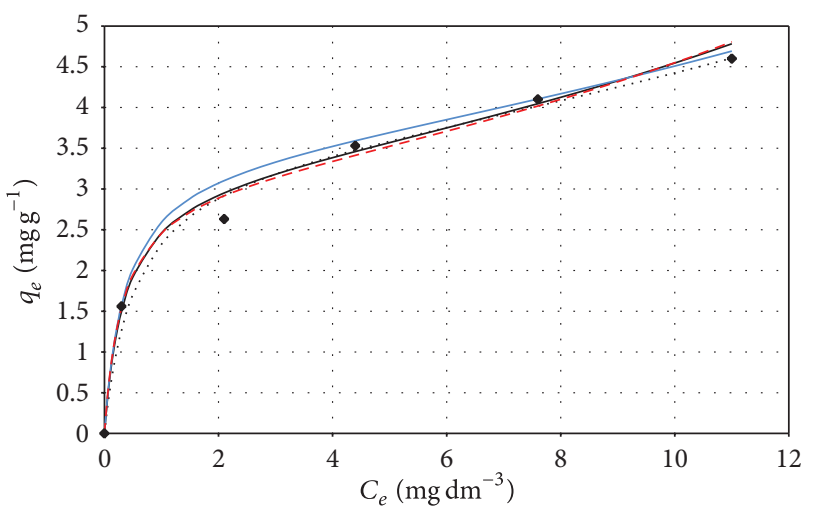

- Exp. data

- Multilayer-ERRSQ

..... Multilayer-2nd-order polynomial form

- Multilayer-EABS

- - - Multilayer-HYBRID

FIGURE 5: Experimental equilibrium data and Fritz-Schlunder (fourparameter model) isotherms of $p$-NP biosorption on $R$. oryzae dead biomass $\left(m 3.00 \mathrm{~g} \mathrm{dm}^{-3}, \mathrm{pH} 6.1 \pm 0.2, T 19 \pm 2^{\circ} \mathrm{C}\right)$.

As stated earlier (Section Introduction), chitin and chitosan are the main components of $R$. oryzae cell walls. Due to the better hydrophilic properties of chitosan, it expands in an aqueous medium, the active sites which predetermine hydrogen bonding, become more pronounced and easily accessible. The amino $\left(-\mathrm{NH}_{2}\right)$ and hydroxyl $(-\mathrm{OH})$ groups serve as the coordination and reaction sites. Besides, the $\mathrm{pKa}$ value of amino group $\left(\mathrm{R}-\mathrm{NH}_{2}\right)$ in the structure of chitosan is 6.3 , and amino group dissociates partly into $\mathrm{R}_{-} \mathrm{NH}_{3}{ }^{+}$even at $\mathrm{pH} 6.1$ (Figure 3). The $\mathrm{pKa}$ value of $p$-nitrophenol is around 7.1, whereby at certain $\mathrm{pH}$ below the $\mathrm{pKa}$ of the dissociating solutes, $p$-nitrophenol exists as neutral form and above the $\mathrm{pKa}$ value, $p$-nitrophenol exists in ionic form [4]. $\mathrm{O}-\mathrm{H}$ bond can be broken off easily, and nitro group causes to earn the resonance stability to structure by helping to the delocalization of negative charge [7]. Hence, there is a possibility of chemical interaction between this positive charge and negative charge existent and delocalized in the anionic structure of the organic molecule (Figure 3). Chitin is carrying on linear amino group per glucose unit and thus exhibitis much higher uptake capacity. The amino group has an electron pair available for coordination and behaves like a strong Lewis base. The amine nitrogen on each chitin monomer has been suggested as the active site for 4-NP adsorption [51].

Hence, it is supposed that the adsorption of $p$-nitrophenol molecules was due mainly to the formation of $\mathrm{H}$-bonds between chitin and chitosan functional groups and $\mathrm{NO}_{2}-$ and $\mathrm{OH}$ - groups in the organic molecules (Figure 3 ).

The relatively high value of the regression coefficient $R^{2}$ obtained through the second polynomial form of the multilayer model $\left(R^{2} 0.9967\right)$ (Table 3$)$ confirmed its applicability for describing the experimental data. The plots presented in Figure 4, however, demonstrated a deviation of all model isotherms for the middle concentration region. Probably, the biosorption of the mononitrophenol was accomplished predominantly on the first biosorbent layers, but the possibility of multilayer sorption, although at a lower extend, could not be neglected.

The comparison between the values of the six error estimating functions and the modes of experimental versus model isotherms outlined the Freundlich (Figure 2) and/or Fritz-Schlunder (Figure 5) equations as the most adequate models describing $p$-NP biosorption on $R$. oryzae. In the context of the current work, the corrected Akaike information criterion $\left(\mathrm{AIC}_{\mathrm{C}}\right)$ was used as to verify the conclusions for the best fitting model withdrawn on bases of error analysis, so to rank the five isotherm models.

The AIC developed by Akaike is a methodology for model selection in a situation where more than one model has been fitted to experimental data and screening of the candidate models is crucial to the objectives of the research work. Akaike's general approach not only allows the best model to be identified, but also allows the ranking of the rest of the models under consideration [46].

The data in Table 4 show that the $\mathrm{AIC}_{\mathrm{C}}$ for the Freundlich model has the minimum $\mathrm{AIC}_{\mathrm{C}}$ value $\left(\mathrm{AIC}_{\mathrm{C}}-14.44\right)$. This implies that the theoretical data obtained from this model fits the experimental results better than the other four equilibrium isotherm equations. Consequently, this statistical tool confirmed the results from the error analysis and proved 
the better correlation of the experimental data with the nonlinear forms of the conventional two-parameter Freundlich equation. The ranking of the isotherm equations was made on the basis of the Relative Akaike Weight (RAW), $\lambda_{i}$, (Table 2). The values of $\lambda_{i}$ (Table 4) clearly distinguished the appropriateness of the five isotherm equations ranking the two-parameter Freundlich model as the first $\left(\lambda_{i} 1.00\right)$ and the four-parameter Fritz-Schlunder model as the second $\left(\lambda_{i} 5.675\right)$ best fitted ones to the experimental data. Similar results had been obtained by Chatterjee et al. [49]. They observed that experimental data gave better fitting to Langmuir than to Redlich-Peterson model using AIC to rank them. The investigations of Mutua [46] outlined that the Freundlich model ranked first among seven isotherm equations used to model the adsorption of $\mathrm{Cu}^{2+}$ and $\mathrm{Cd}^{2+}$ onto bentonite and modified bentonite clay.

Comparative analyses between the presented experimental results and the literature cited biosorption capacity of various $R$. oryzae-based biosorbents were accomplished and presented in Table 5.

Considering the values of the individual system parameters (initial sorbate concentration, biosorbent concentration, etc.), it could be concluded that the maximum biosorption capacity of $R$. oryzae dead biomass towards p-NP $\left(q_{\max }\right.$ $4.6 \mathrm{mg} \mathrm{g}^{-1}$ ) was satisfactory. Besides, the present investigations proved the high efficiency (94\%) of Rhizopus oryzae, obtained at $C_{o} 5 \mathrm{mg} \mathrm{dm}^{-3}$ and $m 3 \mathrm{~g} \mathrm{dm}^{-3}$, as an alternative adsorbent for $p$-NP removal from aqueous phase and revealed the mechanism of the separation process at laboratory scale. Due to the harmful effects of these organic compounds and the urge for sustainable development for the natural water resources at global scale, however, the wastewaters containing them must be treated before being discharged to receiving natural water bodies. Consequently, the future perspectives of the applicability of the proposed "ecofriendly" biosorbent for industrial purposes include large-scale investigations with real wastewaters containing mononitrophenols and/or contaminated natural waters.

\section{Conclusion}

The single-component biosorption of p-NP on Rhizopus oryzae dead biomass from aqueous medium was investigated on the basis of equilibrium studies. The experimental data was modelled and evaluated using five isotherm models and seven optimization and error functions, including the corrected Akaike information criterion $\left(\mathrm{AIC}_{\mathrm{C}}\right)$ as a statistical estimating and ranking tool. The linear transform model provided the highest $R^{2}$ regression coefficient for the case of Redlich-Peterson isotherm. The analysis of the other error functions for linear/nonlinear optimization and $\mathrm{AIC}_{\mathrm{C}}$ outlined the conventional two-parameter Freundlich equation as generally the best-fitting model among the other two-, three-, and four-parameter isotherms applied. The laboratory studies proved the high efficiency (94\% uptake extend) of Rhizopus oryzae dead biomass as an alternative adsorbent for removal of the toxic and recalcitrant organic contaminant $p$-NP from aqueous phase and outlined its future applicability in largescale wastewater treatment technologies.

\section{Nomenclature}

A: $\quad$ Fritz-Schlunder constant, $\mathrm{dm}^{3} \mathrm{~g}^{-1}$

$a_{L}: \quad$ Langmuir isotherm constant, $\mathrm{dm}^{3} \mathrm{~g}^{-1}$

$a_{R}: \quad$ Redlich-Peterson isotherm constant, $\mathrm{dm}^{3} \mathrm{~g}^{-1}$

AIC: $\quad$ Akaike information criterion

$\mathrm{AIC}_{\mathrm{C}}$ : Corrected Akaike information criterion

ARE: The average relative error

B: $\quad$ Fritz-Schlunder constant, $\mathrm{dm}^{3} \mathrm{~g}^{-1}$

$b$ : $\quad$ Redlich-Peterson isotherm constant

$C_{e}: \quad$ Equilibrium adsorbate concentration in the liquid phase, $\mathrm{mg} \mathrm{dm}^{-3}$

$C_{o}$ : Initial adsorbate concentration in the liquid phase, $\mathrm{mg} \mathrm{dm}^{-3}$

$d_{p}: \quad$ Particle diameter, $\mathrm{mm}$

EABS: The sum of the absolute errors

ERRSQ: The sum of the squares of errors

FSch: $\quad$ Fritz-Schlunder model

HYBRID: The hybrid fractional error function

$K_{L}: \quad$ Langmuir isotherm constant, $\mathrm{dm}^{3} \mathrm{~g}^{-1}$

$K_{F}: \quad$ Freundlich isotherm constant, $\mathrm{dm}^{3} \mathrm{~g}^{-1}$

$K_{R}: \quad$ Redlich-Peterson isotherm constant, $\mathrm{dm}^{3} \mathrm{~g}^{-1}$

$K_{1}: \quad$ equilibrium constant for the first layer adsorption in the multilayer isotherm model

$K_{2}: \quad$ Equilibrium constant for multilayer adsorption in the multilayer isotherm model

LTFM: The linear transform model

$m: \quad$ Adsorbent concentration, $\mathrm{g} \mathrm{dm}^{-3}$

MPSD: Marquardt's percent standard deviation

$n$ : $\quad$ number of isotherm parameters

$n_{F}: \quad$ the heterogeneity factor in the Freundlich model

$p: \quad$ Number of experimental data points

$Q_{m}: \quad$ Maximum monolayer adsorption capacity in the multilayer isotherm model, $\mathrm{mg} \mathrm{g}^{-1}$

$q_{e}: \quad$ The equilibrium sorbate concentration in the solid phase, $\mathrm{mg} \mathrm{g}^{-1}$

$q_{e}^{\text {exp }}: \quad$ Experimental $p$-NP equilibrium solid phase concentration, $\mathrm{mg} \mathrm{g}^{-1}$

$q_{e}{ }^{\text {mod }}:$ Model calculated $p$-NP equilibrium solid phase concentration, $\mathrm{mg} \mathrm{g}^{-1}$

$q_{t}$ : The sorption capacity at equilibrium and at time $t, \mathrm{mg} \mathrm{g}^{-1}$

$R^{2}: \quad$ Correlation coefficient

SSR: The sum of the squares for the residual

T: $\quad$ Temperature, $\mathrm{K}$

$t: \quad$ Time, min

$V: \quad$ Solution volume, $\mathrm{dm}^{3}$

$w: \quad$ Adsorbent mass, $g$.

Greek Symbols

$\alpha$ : Fritz-Schlunder exponent

$\beta$ : Fritz-Schlunder exponent

$\lambda$ : Maximum absorbance wavelength, $\mathrm{nm}$

$\lambda_{i}$ : Akaike weight for the $i$ th model

$\Delta_{i}$ : The difference between the $\mathrm{AIC}_{\mathrm{C}}$ of the best fitting model and that of model $i$. 


\section{References}

[1] A. Ayar, S. Gürsal, A. A. Gürten, and O. Gezici, "On the removal of some phenolic compounds from aqueous solutions by using a sporopollenin-based ligand-exchange fixed bed-isotherm analysis," Desalination, vol. 219, no. 1-3, pp. 160-170, 2008.

[2] K. Lin, J. Pan, Y. Chen, R. Cheng, and X. Xu, "Study the adsorption of phenol from aqueous solution on hydroxyapatite nanopowders," Journal of Hazardous Materials, vol. 161, no. 1, pp. 231-240, 2009.

[3] W. Huang, C. Yao, S. Jin, S. Ying, and X. Shen, "Sorption of pnitrophenol onto sediment in the presence of cetylpyridinium chloride and $\mathrm{Pb}\left(\mathrm{NO}_{3}\right)_{2}$ : influence of $\mathrm{pH}$," Journal of Hazardous Materials, vol. 155, no. 1-2, pp. 225-229, 2008.

[4] W. S. W. Ngah and S. Fatinathan, "Chitosan flakes and chitosanGLA beads for adsorption of p-nitrophenol in aqueous solution," Colloids and Surfaces A, vol. 277, no. 1-3, pp. 214-222, 2006.

[5] P. Barkakati, A. Begum, M. L. Das, and P. G. Rao, "Adsorptive separation of Ginsenoside from aqueous solution by polymeric resins: equilibrium, kinetic and thermodynamic studies," Chemical Engineering Journal, vol. 161, no. 1-2, pp. 34-45, 2010.

[6] I. Uzun and F. Güzel, "Kinetics and thermodynamics of the adsorption of some dyestuffs and p-nitrophenol by chitosan and MCM-chitosan from aqueous solution," Journal of Colloid and Interface Science, vol. 274, no. 2, pp. 398-412, 2004.

[7] I. Uzun and F. Güzel, "Rate studies on the adsorption of some dyestuffs and p-nitrophenol by chitosan and monocarboxymethylated( $\mathrm{mcm})$-chitosan from aqueous solution," Journal of Hazardous Materials, vol. 118, no. 1-3, pp. 141-154, 2005.

[8] S. J. Allen and B. Koumanova, "Decolourization of water/ wastewater using adsorption (Review)," Journal of the University of Chemical Technology and Metallurgy, vol. 40, no. 3, pp. 175-192, 2005.

[9] B. J. Mcafee, W. D. Gould, J. C. Nadeau, and A. C. A. Da Costa, "Biosorption of metal ions using chitosan, chitin, and biomass of Rhizopus oryzae," Separation Science and Technology, vol. 36, no. 14, pp. 3207-3222, 2001.

[10] Q. I. Yang, J. L. Wang, and Z. Xing, "Biosorption of cadmium by fungal biomass of Aspergillus niger," Biomedical and Environmental Sciences, vol. 18, no. 3, pp. 141-145, 2005.

[11] K. C. Bhainsa and S. F. D'Souza, "Removal of copper ions by the filamentous fungus, Rhizopus oryzae from aqueous solution," Bioresource Technology, vol. 99, no. 9, pp. 3829-3835, 2008.

[12] W. Lang, C. Dejma, S. Sirisansaneeyakul, and N. Sakairi, "Biosorption of nonylphenol on dead biomass of Rhizopus arrhizus encapsulated in chitosan beads," Bioresource Technology, vol. 100, no. 23, pp. 5616-5623, 2009.

[13] B. Ma, H. Chen, M. Xu et al., "Adsorption of polycyclic aromatic hydrocarbons (PAHs) on Rhyzopus Oryzae cell wall: application of cosolvent models for validating the cell wall-water partition coefficient, Approaches for Measuring Kinetic and Thermodynamic Properties of Processes at the Mineral/Water Interface," in Proceedings of the International Annual Meetings ASA, CSSA and SSSA, pp. 303-304, Long Beach, Calif, USA, November 2010.

[14] R. R. Dash, C. Balomajumder, and A. Kumar, "Cyanide removal by combined adsorption and biodegradation process," Iranian Journal of Environmental Health Science \& Engineering, vol. 3, no. 2, pp. 91-96, 2006.
[15] S. Ghosh, S. K. Das, A. K. Guha, and A. K. Sanyal, "Adsorption behavior of lindane on Rhizopus oryzae biomass: physicochemical studies," Journal of Hazardous Materials, vol. 172, no. 1, pp. 485-490, 2009.

[16] S. K. Das, J. Bhowal, A. R. Das, and A. K. Guha, "Adsorption behavior of rhodamine B on Rhizopus oryzae biomass," Langmuir, vol. 22, no. 17, pp. 7265-7272, 2006.

[17] B. Koumanova, P. Peeva, S. J. Allen et al., "Biosorption from aqueous solutions by eggshell membranes and Rhizopus oryzae: equilibrium and kinetic studies," Journal of Chemical Technology \& Biotechnology, vol. 77, pp. 539-545, 2002.

[18] J. S. Rhee, M. W. Jung, and K. J. Paeng, "Evaluation of chitin and chitosan as a sorbent for the preconcentration of phenol and chlorophenols in water," Analytical Sciences, vol. 14, no. 6, pp. 1089-1092, 1998.

[19] O. Hamdaoui and E. Naffrechoux, "Modeling of adsorption isotherms of phenol and chlorophenols onto granular activated carbon. Part II. Models with more than two parameters," Journal of Hazardous Materials, vol. 147, no. 1-2, pp. 401-411, 2007.

[20] Q. S. Liu, T. Zheng, P. Wang, J. P. Jiang, and N. Li, "Adsorption isotherm, kinetic and mechanism studies of some substituted phenols on activated carbon fibers," Chemical Engineering Journal, vol. 157, no. 2-3, pp. 348-356, 2010.

[21] Z. Zhang, Z. Zhang, Y. Fernández et al., "Adsorption isotherms and kinetics of methylene blue on a low-cost adsorbent recovered from a spent catalyst of vinyl acetate synthesis," Applied Surface Science, vol. 256, no. 8, pp. 2569-2576, 2010.

[22] J. Rahchamani, H. Z. Mousavi, and M. Behzad, "Adsorption of methyl violet from aqueous solution by polyacrylamide as an adsorbent: isotherm and kinetic studies," Desalination, vol. 267, no. 2-3, pp. 256-260, 2011.

[23] V. M. Vučurović, R. N. Razmovski, and M. N. Tekić, "Methylene blue (cationic dye) adsorption onto sugar beet pulp: equilibrium isotherm and kinetic studies," Journal of the Taiwan Institute of Chemical Engineers, vol. 43, no. 1, pp. 108-111, 2012.

[24] K. Y. Foo and B. H. Hameed, "Insights into the modeling of adsorption isotherm systems," Chemical Engineering Journal, vol. 156, no. 1, pp. 2-10, 2010.

[25] K. V. Kumar, K. Porkodi, and F. Rocha, "Isotherms and thermodynamics by linear and non-linear regression analysis for the sorption of methylene blue onto activated carbon: comparison of various error functions," Journal of Hazardous Materials, vol. 151, no. 2-3, pp. 794-804, 2008.

[26] H. León-Santiestebán, M. Meraz, K. Wrobel, and A. Tomasini, "Pentachlorophenol sorption in nylon fiber and removal by immobilized Rhizopus oryzae ENHE," Journal of Hazardous Materials, vol. 190, no. 1-3, pp. 707-712, 2011.

[27] M. A. Abdullah, L. Chiang, and M. Nadeem, "Comparative evaluation of adsorption kinetics and isotherms of a natural product removal by Amberlite polymeric adsorbents," Chemical Engineering Journal, vol. 146, no. 3, pp. 370-376, 2009.

[28] R. Lancelot, M. Lesnoff, and J. J. McDermott, "Use of Akaike information criteria for model selection and inference. An application to assess prevention of gastrointestinal parasitism and respiratory mortality of Guinean goats in Kolda, Senegal," Preventive Veterinary Medicine, vol. 55, no. 4, pp. 217-240, 2002.

[29] J. Ødegård, J. Jensen, G. Klemetsdal, P. Madsen, and B. Heringstad, "Genetic analysis of somatic cell score in Norwegian cattle using random regression test-day models," Journal of Dairy Science, vol. 86, no. 12, pp. 4103-4114, 2003. 
[30] C. P. McDonald and N. R. Urban, "Using a model selection criterion to identify appropriate complexity in aquatic biogeochemical models," Ecological Modelling, vol. 221, no. 3, pp. 428-432, 2010.

[31] A. Vaia and N. V. Sahinidis, "Simultaneous parameter estimation and model structure determination in FTIR spectroscopy by global MINLP optimization," Computers and Chemical Engineering, vol. 27, no. 6, pp. 763-779, 2003.

[32] Y. Li, A. M. Rauth, and X. Y. Wu, "Prediction of kinetics of doxorubicin release from sulfopropyl dextran ion-exchange microspheres using artificial neural networks," European Journal of Pharmaceutical Sciences, vol. 24, no. 5, pp. 401-410, 2005.

[33] A. A. M. Daifullah and B. S. Girgis, "Removal of some substituted phenols by activated carbon obtained from agricultural waste," Water Research, vol. 32, no. 4, pp. 1169-1177, 1998.

[34] S. J. Allen, Q. Gan, R. Matthews, and P. A. Johnson, "Comparison of optimised isotherm models for basic dye adsorption by kudzu," Bioresource Technology, vol. 88, no. 2, pp. 143-152, 2003.

[35] M. C. Ncibi, "Applicability of some statistical tools to predict optimum adsorption isotherm after linear and non-linear regression analysis," Journal of Hazardous Materials, vol. 153, no. 1-2, pp. 207-212, 2008.

[36] I. Langmuir, "The constitution and fundamental properties of solids and liquids. Part I. Solids," The Journal of the American Chemical Society, vol. 38, no. 2, pp. 2221-2295, 1916.

[37] H. Freundlich, "Über die adsorption in iösungen," The Journal of Physical Chemistry, vol. 57, pp. 385-470, 1907.

[38] O. Redlich and D. L. Peterson, "A useful adsorption isotherm," The Journal of Physical Chemistry, vol. 63, pp. 1024-1026, 1959.

[39] J. Wang, C. P. Huang, H. E. Allen, D. K. Cha, and D. W. Kim, "Adsorption characteristics of dye onto sludge particulates," Journal of Colloid and Interface Science, vol. 208, no. 2, pp. 518-528, 1998.

[40] W. Fritz and E. U. Schluender, "Simultaneous adsorption equilibria of organic solutes in dilute aqueous solutions on activated carbon," Chemical Engineering Science, vol. 29, no. 5, pp. 1279-1282, 1974.

[41] M. I. El-Khaiary and G. F. Malash, "Common data analysis errors in batch adsorption studies," Hydrometallurgy, vol. 105, no. 3-4, pp. 314-320, 2011.

[42] A. Gunay, "Application of nonlinear regression analysis for ammonium exchange by natural (Bigadiç) clinoptilolite," Journal of Hazardous Materials, vol. 148, no. 3, pp. 708-713, 2007.

[43] M. Hadi, M. R. Samarghandi, and G. McKay, "Equilibrium twoparameter isotherms of acid dyes sorption by activated carbons: study of residual errors," Chemical Engineering Journal, vol. 160, no. 2, pp. 408-416, 2010.

[44] A. Kapoor and R. T. Yang, "Correlation of equilibrium adsorption data of condensible vapours on porous adsorbents," Gas Separation and Purification, vol. 3, no. 4, pp. 187-192, 1989.

[45] D. W. Marquardt, "An algorithm for least squares estimation of non-linear parameters," Journal of the Society for Industrial and Applied Mathematics, vol. 11, pp. 431-441, 1963.

[46] F. M. Mutua, "The use of the Akaike information criterion in the identification of an optimum flood frequency model," Hydrological Sciences Journal, vol. 39, no. 3, pp. 235-244, 1994.

[47] J. F. Porter, G. McKay, and K. H. Choy, "The prediction of sorption from a binary mixture of acidic dyes using single- and mixed-isotherm variants of the ideal adsorbed solute theory,"
Chemical Engineering Science, vol. 54, no. 24, pp. 5863-5885, 1999.

[48] A. Seidel and D. Gelbin, "On applying the ideal adsorbed solution theory to multicomponent adsorption equilibria of dissolved organic components on activated carbon," Chemical Engineering Science, vol. 43, no. 1, pp. 79-88, 1988.

[49] S. Chatterjee, S. K. Das, R. Chakravarty, A. Chakrabarti, S. Ghosh, and A. K. Guha, "Interaction of malathion, an organophosphorus pesticide with Rhizopus oryzae biomass," Journal of Hazardous Materials, vol. 174, no. 1-3, pp. 47-53, 2010.

[50] Y. Yang, Z. Li, G. Wang et al., "Computational identification and analysis of the key biosorbent characteristics for the biosorption process of Reactive Black 5 onto fungal biomass," PloS ONE, vol. 7, no. 2, pp. 1-8, 2012.

[51] T. Şişmanoğlu, "Removal of some fungicides from aqueous solution by the biopolymer chitin," Colloids and Surfaces A, vol. 297, no. $1-3$, pp. $38-45,2007$. 

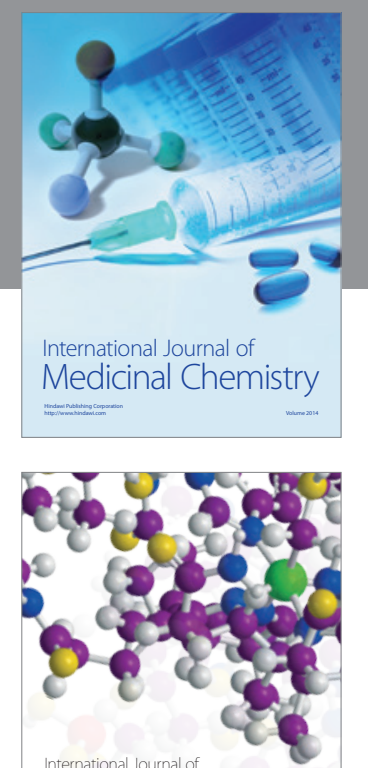

\section{Carbohydrate} Chemistry

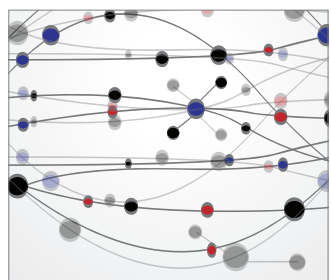

The Scientific World Journal
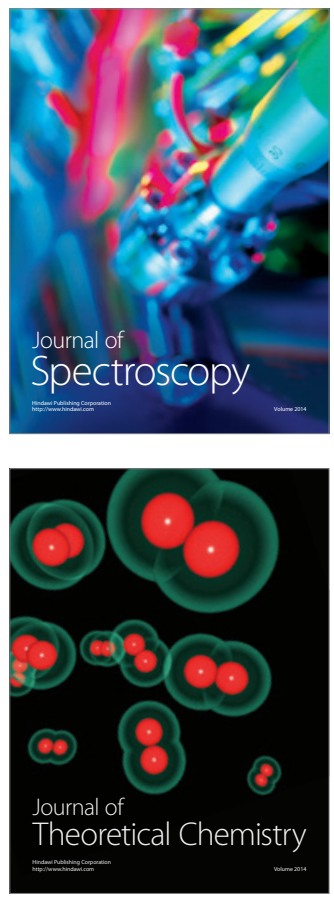
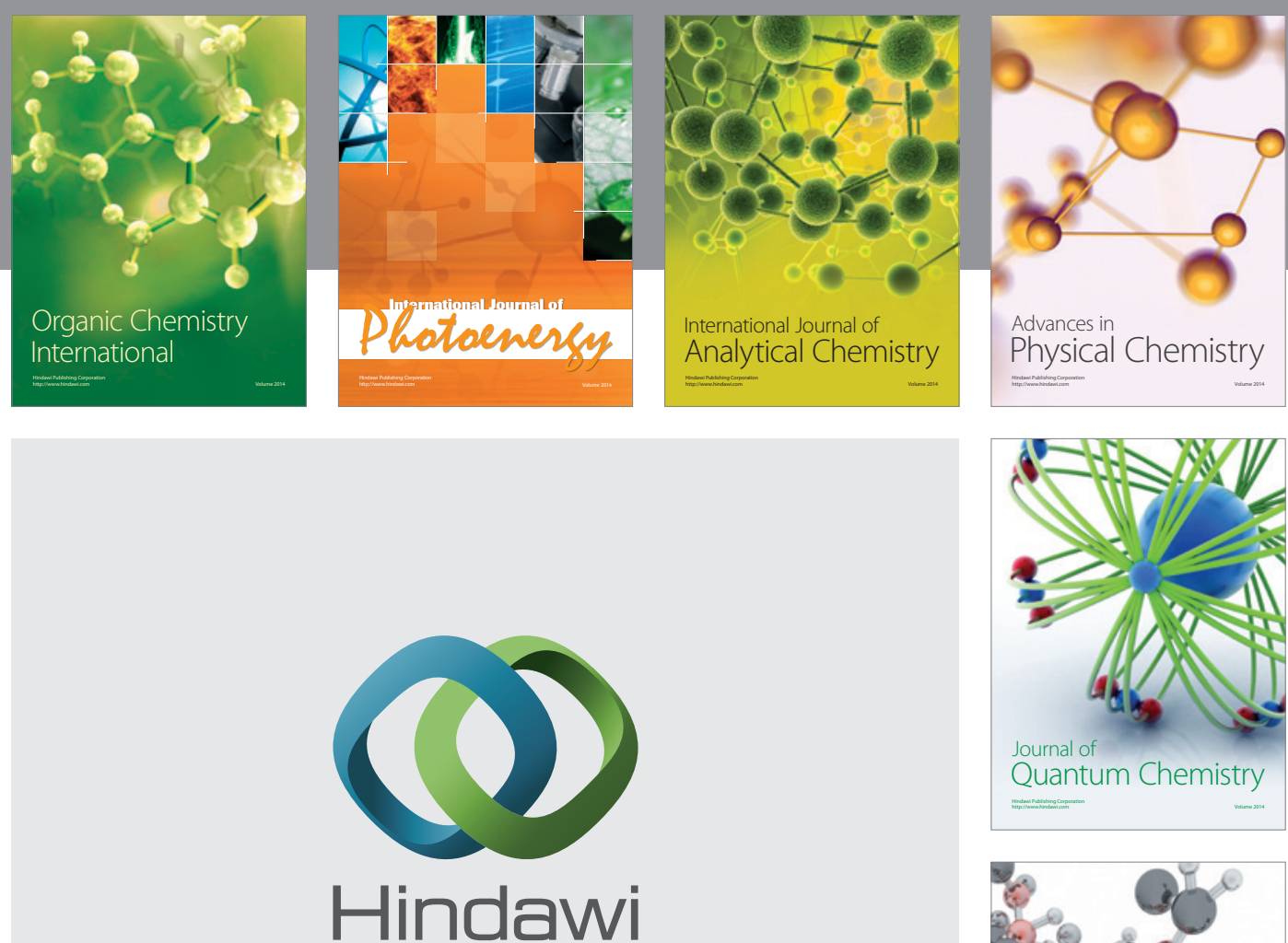

Submit your manuscripts at

http://www.hindawi.com

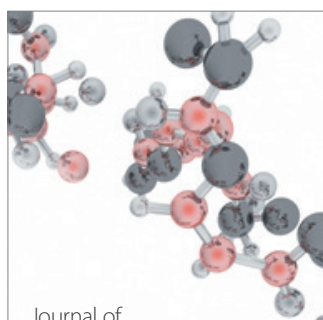

Analytical Methods

in Chemistry

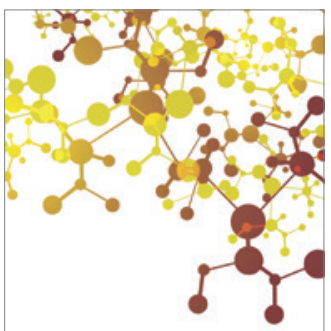

Journal of

Applied Chemistry

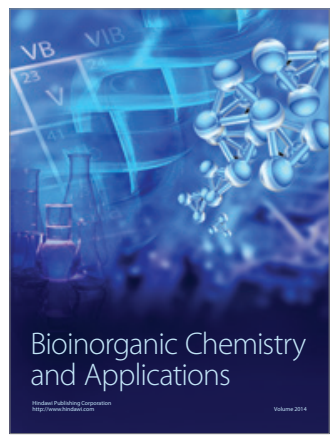

Inorganic Chemistry
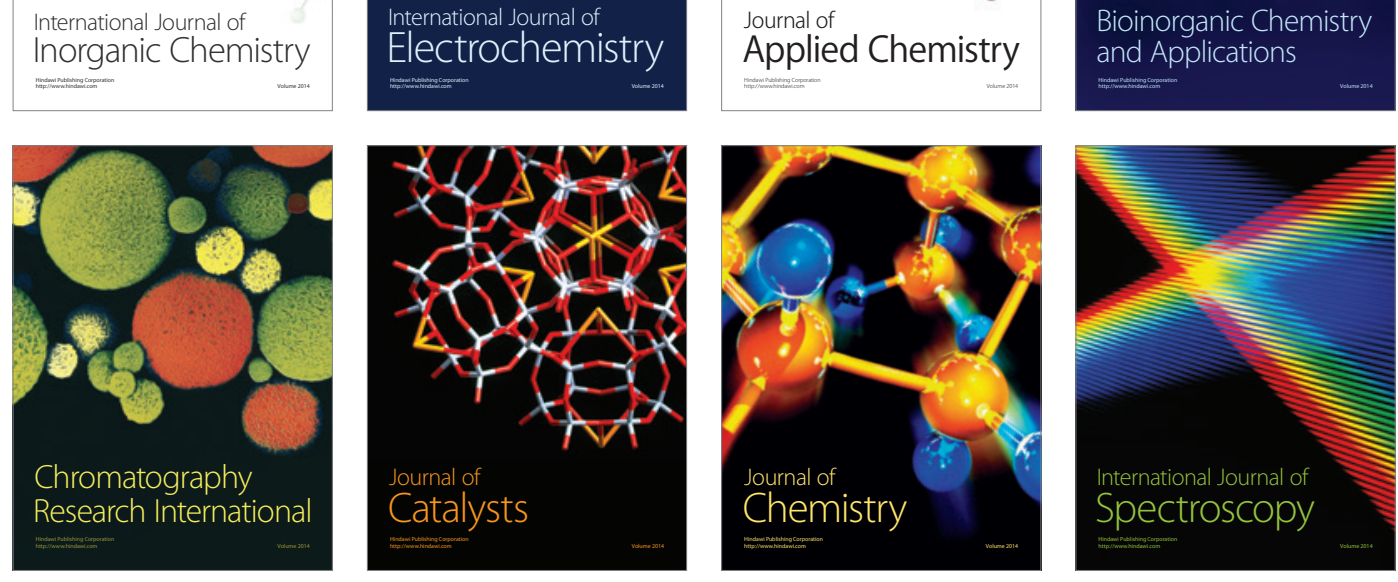